\title{
IMPLEMENTAÇÃO DE CONCEITOS DE ERP COMO APOIO NA GESTÃO DA PRODUÇÃO DE UMA TORNEARIA DE PEQUENO PORTE
}

\author{
Beatriz Cristina Ferreira Machado - FIC/UNIS - beatriz.machado@ alunos.unis.edu.br \\ Iago Aquiles Machado Vieira - FIC/UNIS - iago.machado@alunos.unis.edu.br \\ Matheus Hernesto Mendes Alves - FIC/UNIS- matheus.henesto@alunos.unis.edu.br \\ Rodolfo de Souza Cunha - FIC/UNIS - rodolfo.cunha@alunos.unis.edu.br ${ }^{1}$ \\ Tiago BittencourtNazaré - FIC/UNIS/DOCTUM - tiago@ unis.edu.br²
}

\begin{abstract}
RESUMO: Nos dias atuais, muitas empresas de pequeno e médio porte ainda não possuem um sistema de gestão de dados capaz de auxiliar efetivamente na gestão dos processos e tomadas de decisão. Em meio a esse desafio muitas organizações estão adotando sistemas Enterprise Resource Planning (ERP), os quais são capazes de organizar e estruturar informações para um melhor gerenciamento e controle de processos, além de realizar a integração das mesmas, melhorando a assertividade da gestão, reduzindo custos e tempo para todos os setores que forem contemplados nesta melhoria.Devido ao aumento da demanda de produção e do relacionamento estreito junto aos clientes, foi realizada uma análise em uma Tornearia de pequeno porte, identificando os pontos de melhoria nos processos que englobam, desde o recebimento do pedido, até a entrega do produto final. A padronização de seus processos também foi vista como necessidade para o gerenciamento da produção e entrega de seus produtos. O presente artigo teve como objetivo realizar um estudo empírico sobre o ERP. Foram realizadas pesquisas bibliográficas sobre os conceitos e a aplicação de técnicas, abordando os benefícios que esse sistema pode oferecer após implementado em uma tornearia de pequeno porte. Conclui-se que com a implantação dos conceitos de ERP, a Tornearia passaria a gerenciar as informações de produção de maneira mais clara, prevendo o custo e prazo de entrega do produto com mais assertividade, gerando maior confiança e adesão por parte dos clientes.
\end{abstract}

Palavras-chave: ERP; Cliente; Padronização; Produto.

\section{INTRODUÇÃO}

Segundo Teixeira (2017), as micro e pequenas empresas (MPE) têm ganhado evidência em vários países devido à sua importância econômica, principalmente, enquanto geração de empregos e renda, em um cenário de desaceleração da economia mundial.

De acordo com o IBGE (2010), no Brasil, as MPE's têm exercido uma participação expressiva na economia, totalizando $99 \%$ do total de empresas, com $20 \%$ na participação do PIB nacional.

Segundo pesquisa do SEBRAE e DIEESE (2011), essas empresas representam quase $52 \%$ dos postos de trabalho do setor privado.

Em contrapartida, segundo pesquisa elaborada pelo SEBRAE (2016), a taxa de mortalidade das MPE's no Brasil apurada para as empresas constituídas e registradas nas juntas comerciais dos Estados no ano de 2012, mostra que 23,4\% encerraram suas atividades com até dois anos de existência, e 45,0\% não sobrevivem além dos quatro anos.

Conforme Nogueira, (2013) nos últimos anos houve um aumento da automação dos processos administrativos das PME's. Trata-se de uma quebra de paradigmas, considerando que há pouco menos de uma década somente grandes organizações empregavam o uso de softwares para gestão.

O’brien e Marakas (2013) definem que o sistema ERP é uma evolução do MRP (Material Requirements Planning), o qual é formado por um conjunto de aplicações capazes de integrar os processos empresariais de finanças, manufatura, suprimentos, logística, recursos humanos e vendas em um só sistema de informação, o que viabiliza o registro de dados em um único local de armazenamento e interligando-os em tempo real. 
Para Fornazaro (2011), o ERP provê o suporte necessário à empresa na busca para contenção de custos e obtenção de lucro, promovendo um ganho de produtividade, maior visibilidade da empresa no mercado, facilitando o relacionamento com clientes e fornecedores, possibilitando um maior crescimento da empresa e consolidando a sua marca.

Após análise dos principais problemas encontrados na Tornearia, observou-se a necessidade de automatização dos processos administrativos, com o objetivo de integrar os procedimentos relativos à produção e faturamento da Tornearia. A implantação de um sistema ERP seria fundamental nesse processo de integração, entretanto, o elevado custo para aquisição e implantação dos sistemas ERP consagrados não é compatível com o faturamento da empresa em estudo, o que guiou as estratégias na direção de uma opção gratuita do software, das diversas existentes no mercado.

Deste modo, o presente artigo tem como objetivo demonstrar de forma prática os conceitos e aplicabilidade de sistema de ERP (Enterprise Resource Planning) em uma tornearia de pequeno porte, dando ênfase nos benefícios do ponto de vista de gestão administrativa e produção, agregados através da utilização de uma ferramenta gratuita de ERP.

\section{REVISÃO DE LITERATURA}

\subsection{O potencial das Micro e Pequenas Empresas (MPE)}

De acordo com a Lei Geral das Microempresas e Empresas de Pequeno Porte, a Lei Complementar $\mathrm{n}^{\circ} 123$, de 14 de dezembro de 2006, considera-se microempresa a sociedade empresária, a sociedade simples, a empresa individual de responsabilidade limitada e o empresário, devidamente registrados nos órgãos competentes que aufiram, em cada ano-calendário, receita bruta superior a $\mathrm{R} \$ 360.000,00 \mathrm{e}$ igual ou inferior a $\mathrm{R} \$ 4.800 .000,00$.

Outra definição é adotada pelo Serviço Brasileiro e Apoio às Micro e Pequenas Empresas (SEBRAE, 2011), que classifica as empresas tanto em relação ao faturamento bruto anual quanto em relação ao número de funcionários que a mesma possui, limitando as microempresas àquelas que empregam até 9 pessoas, no caso de comércio e serviços, ou até 19pessoas, no caso dos setores industrial ou de construção.

Já as pequenas empresas são definidas como as que empregam de 10 a 49 pessoas, no caso de comércio e serviços, e de 20 a 99 pessoas, no caso de indústria e empresas de construção, conforme mostra o quadro 1.

Quadro 1: Classificação do porte da empresa com relação ao número de empregados

\begin{tabular}{|c|c|c|}
\hline \multirow{2}{*}{ PORTE } & \multicolumn{2}{|l|}{ SETORES } \\
\hline & INDÚSTRIA & COMÉRCIO E SERVIÇOS \\
\hline Microempresa & Até 19 pessoas empregadas & Até 9 pessoas ocupadas \\
\hline Pequena empresa & De 20 a 99 pessoas empregadas & $\begin{array}{llll}\text { De } 10 \text { a } & 10 & \text { pessoas } \\
\text { empregadas } & & \end{array}$ \\
\hline Média empresa & \begin{tabular}{|llll}
$\begin{array}{l}\text { De } 100 \text { a } \\
\text { empregadas }\end{array}$ & & pessoas \\
\end{tabular} & $\begin{array}{llll}\text { De } 50 \text { a } 99 & \text { pessoas } \\
\text { empregadas } & & \\
\end{array}$ \\
\hline Grande empresa & \begin{tabular}{|lcc}
$500 \quad$ ou & mais pessoas \\
empregadas
\end{tabular} & $\begin{array}{llll}100 \quad \text { ou mais } & \text { pessoas } \\
\text { empregadas }\end{array}$ \\
\hline
\end{tabular}

Fonte: SEBRAE, 2013. Adaptado pelo autor

De acordo com Padoveze e Martins (2014), as organizações são caracterizadas por uma série de objetivos específicos, que, de certo modo, estão associados com a 
produção e venda de produtos, mercadorias e/ou serviços. O prefixo "micro" e o adjetivo "pequena" são empregados para mensurar seu tamanho, que, se tratando de uma empresa está relacionado a duas variáveis principais: número de funcionários e faturamento.

Conforme o SEBRAE (2016), as pequenas empresas são definidas da seguinte maneira: microempreendedor individual (MEI) o faturamento anual é de até sessenta mil reais, microempresa (ME) com faturamento anual de até trezentos e sessenta mil reais, empresa de pequeno porte (EPP) com faturamento anual entre trezentos e sessenta mil e 3,6 milhões e o pequeno produtor rural com propriedade com até quatro módulos fiscais ou faturamento anual de até 3,6 milhões.

Segundo Azevedo (2013), no Brasil, a importância socioeconômica das MPE pode ser evidenciada através dos números. Segundo o SEBRAE (2012), as MPE representam 98,5\% do total de empresas do país, atuam nos setores industrial, comercial e de serviços, e ocupam $60 \%$ da oferta de emprego, gerando $21 \%$ do Produto Interno Bruto (PIB). Exercem o papel de principais geradoras de riqueza dentro do comércio nacional, sendo que elas representam 53,4\% do PIB brasileiro deste setor. No PIB da indústria, a atuação das micro e pequenas $(22,5 \%)$ já está próxima de alcançar a participação das médias empresas $(24,5 \%)$. Além disso, no setor de serviços, mais de um terço da produção nacional $(36,3 \%)$ origina-se nos pequenos negócios.

Conforme Everton Junior (2017), no geral as MPE's retratam uma gestão centralizada na figura do seu proprietário e/ou no chefe da família, visto que aproximadamente $50 \%$ das mesmas é constituído por empresas familiares. Devido a este fato, são unidades produtivas extremamente dependentes de decisões unipessoais.

De acordo com Nascimento et al. (2013), apesar da relevância das MPE's para a economia e o desenvolvimento regional, é possível constatar altos índices de mortalidade precoce de micro e pequenas empresas gerados por vários fatores.

Segundo Amorim e Abreu (2017), as MPE's encontram dificuldades para alcançar a meta de crescimento contínuo, ou até mesmo de permanecer no mercado com o decorrer do tempo, pois existem vários fatores que comprometem o sucesso dessas organizações.

\subsection{Enterprise Resource Planning (ERP)}

Dentre várias definições o ERP (Enterprise Resource Planning) pode ser considerado, em síntese, um software que automatiza os processos empresariais. De acordo com Pinheiro (2011), ele é uma ferramenta de T.I., criada com a motivação de integrar processos chave das empresas.

Moraes, e Escrivão Filho (2004) apud Fornazaro (2011), relataram que a ferramenta auxilia a tomada de decisão e gerenciamento estratégico do negócio, aumentando a capacidade dos gerentes e administradores da empresa de encontrar e resolver antecipadamente os problemas referentes a processos, operações $\mathrm{e}$ planejamento da empresa.

O autor Matos (2010), cita que um dos benefícios referentes à implantação de um sistema ERP é a adoção das melhores práticas de negócio trazidas pelas funcionalidades do mesmo, fato que viabiliza ganhos de produtividade e melhorias no fluxo e compartilhamento de informações entre diferentes áreas da mesma empresa.

Escolher o software ERP mais adequado aos processos e peculiaridades da empresa é um aspecto crucial (Chandrakumar\&Parthasarathy, 2016; Garg\&Garg, 2014; Ram et al., 2013) pois tal escolha influencia diretamente nos benefícios advindos da implantação do sistema. 
Conforme Santos (2010), o ERP auxilia na melhoria do fluxo de informações entre todas as atividades transacionais e não transacionais da empresa como: logística, fabricação, finanças, recursos humanos, dentre outros. Devido a esta integração, potencializam-se benefícios quantitativos e qualitativos diretos, como uma maior eficiência e produtividade dos processos, redução de custos diretos e a elevação do nível de gestão e controle; sem mencionar os benefícios alcançados ao longo do tempo, como a ganhos enquanto satisfação do cliente e dos colaboradores, maior agilidade nas tomadas de decisão e a crescente inovação tecnológica.

Para a implantação de uma solução ERP, é necessário, previamente, ter pleno conhecimento das atividades e funcionamento da empresa. Haberkorn (2007) aponta que a maioria dos sistemas de mercado apresenta, em suma, as mesmas funcionalidades básicas, as quais atenderiam perfeitamente a realidade da maioria das corporações e suas necessidades.

O Brasil é o $9^{\circ}$ maior mercado de software e serviços de TI do mundo (Associação Brasileira de Empresas de Software - ABES, 2017), sendo o país como maior volume de investimentos em Tecnologia da Informação na América Latina. O mercado doméstico de hardwares, softwares, serviços e exportações de TI, movimentar aproximadamente de US\$ 38 bilhões durante o ano de 2017. A figura 1 representa a distribuição do mercado mundial de ERP, no ano de 2012.

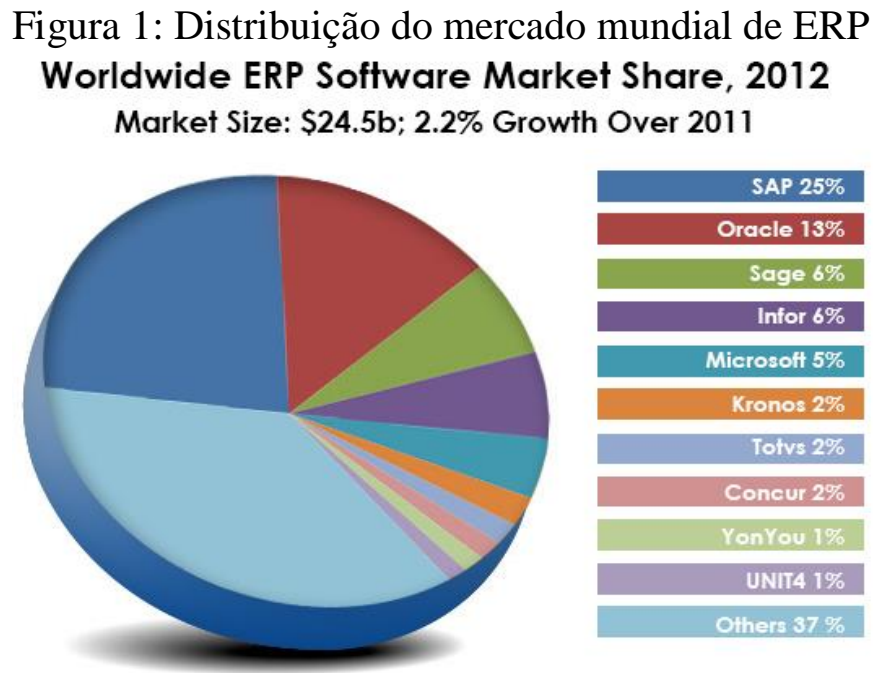

Fonte: TI ESPECILISTAS (2014)

De acordo com a revista Computerworld (2018), os sistemas comercializados pelas empresas: Totvs, SAP e Oracle respondem por81\% do mercado de ERP no Brasil. No topo da lista encontra-se a ferramenta ERP da TOTVS, com 35\%, acompanhada de perto pelas soluções da $S A P(31 \%)$ e Oracle $(15 \%)$. Os dados foram retirados da $29^{a}$ Pesquisa Anual do GVcia, Centro de Tecnologia de Informação Aplicada da Escola de Administração de Empresas de São Paulo da Fundação Getulio Vargas (FGV/EAESP).

\subsection{Sistema ERP MarketUP (ERP)}

Apesar da implantação de sistemas ERP representarem um benefício para as empresas que o adotam, segundo Turbanet al. (2010), este processo implica custos e riscos elevados, em virtude de sua complexidade. 
Estes fatores, em muitos casos, impossibilitam que as empresas de pequeno porte, que possuem recursos limitados, façam uso deste tipo de tecnologia para gerir seus negócios.

Nesta lógica, os sistemas Free Open Source, ou denominados sistemas livres, como é o caso do MarketUP, tornam-se uma alternativa atraente para as empresas interessadas, ou que necessitam realizar uma gestão mais arrojada e assertiva dos processos de seus empreendimentos.

De acordo com o website da MarketUP, a empresa trata-se de um startup inovador que acredita no impacto dos micros e pequenos empreendedores no desenvolvimento econômico do país. Além disso, usam, através da tecnologia, soluções que vão desde o gerenciamento do negócio, a estratégias que melhoram as vendas e reposição de estoque e relacionamento com clientes.

Devido ao reduzido volume de processos presentes na Tornearia e baixa complexidade dos mesmos, a gama de soluções presentes na ferramenta em questão se mostram compatíveis e adequados para a realidade da empresa.

A decisão pelo o uso do sistema gratuito MarketUP foi ainda mais relevante após verificação dos usuários da plataforma, empresas consagradas de mercado como Unilever, FIAT, Google, Unimed, DELL, entre outras que acreditam na ferramenta como um canal diferenciado para realizarem suas ações de divulgação de produtos e serviços. Outro fator determinante é a existência de uma comunidade virtual para discussão e compartilhamento de tutoriais e experiências de utilização. Aliado a estes fatos o programa disponibiliza uma versão em português, além de possuir um layout intuitivo, tornando-o um software user friendly.

\section{METODOLOGIA}

O presente trabalho teve embasamento teórico através de revisão bibliográfica, que de acordo com Gil (2010) deve ser elaborada por meio dos registros disponíveis e fundamentada em artigos científicos, revistas online, legislações e livros referentes ao assunto. Diante da pesquisa realizada, foram mapeados os principais problemas e verificou-se a necessidade da aplicação de uma ferramenta para integrar os processos administrativos e de produção de uma tornearia de pequeno porte.

O objetivo da análise foi identificar os benefícios e oportunidades de melhoria na Tornearia, através da utilização do sistema ERP (Enterprise Resource Planning) na gestão da produção, verificando aplicabilidades dos conceitos e melhor atendimento custo benefício para microempreendedor. Após a identificação dos problemas existentes nos processos, com o intuito de otimizar a produção, analisou-se a viabilidade da implementação de um software de ERP gratuito que se mostra compatível e adequado para a realidade da empresa.

A pesquisa ainda conta com uma breve introdução na definição de micro e pequenas empresas, bem como uma análise de uma empresa alvo para verificação dos principais problemas, e uma proposta de implantação de um software de ERP gratuito.

\subsection{Contextualizando a situação da empresa}

Para a aplicação da ferramenta de ERP, foi tomado como objeto de estudo uma tornearia de pequeno porte na cidade de Cataguases - MG, a qual atua no mercado há 15 anos e trabalha na produção de roldanas, buchas, parafusos entre outros itens do mesmo segmento. A microempresa conta com apenas dois funcionários em seu quadro, sendo um deles o próprio proprietário. 
O processo de produção segue um fluxo de atendimento, conforme figura 2, no qual o cliente fornece a matéria-prima com as especificações dos produtos a serem manufaturados, os quais serão entregues mediante prazos pré-acordados entre as partes.

Figura 2: Fluxograma dos processos da Tornearia

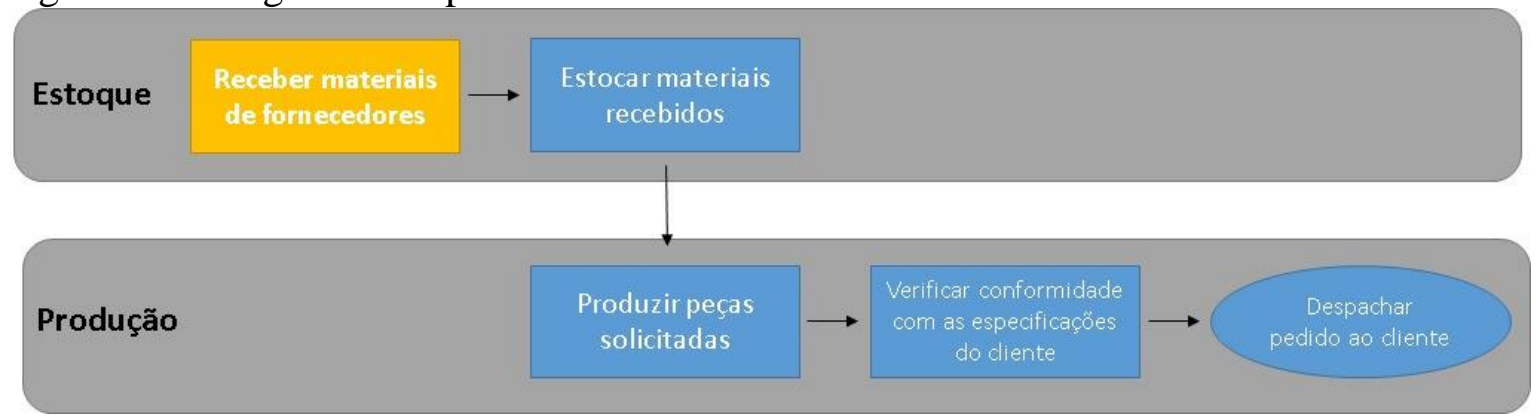

Fonte: Elaborada pelos autores.

Conforme figura 3, foram observados alguns pontos deficitários, do ponto de vista de gestão de processos, que influenciam negativamente no processo produtivo e de relacionamento com o cliente. Devido à falta de automatização no processo e recebimento dos pedidos, podem ocorrer divergências entre valores cobrados para peças iguais, assim como, também no estabelecimento de SLA's (Service LevelAgreement) de atendimentos por peça. Outro ponto de atenção é com relação à emissão de notas fiscais de produtos a serem entregues, uma vez que o processo ocorre de forma manual (montagem e emissão), ocasionando perda de tempo operacional, dado que este procedimento não agrega valor direto à atividade fim da empresa. A relativa falta de controle das notas fiscais, emitidas e recebidas, está intrinsecamente ligada, de forma negativa, as dificuldades também encontradas na execução do processo de gestão do faturamento mensal.

Figura 3: Diagrama de Causa e Efeito dos processos da Tornearia.

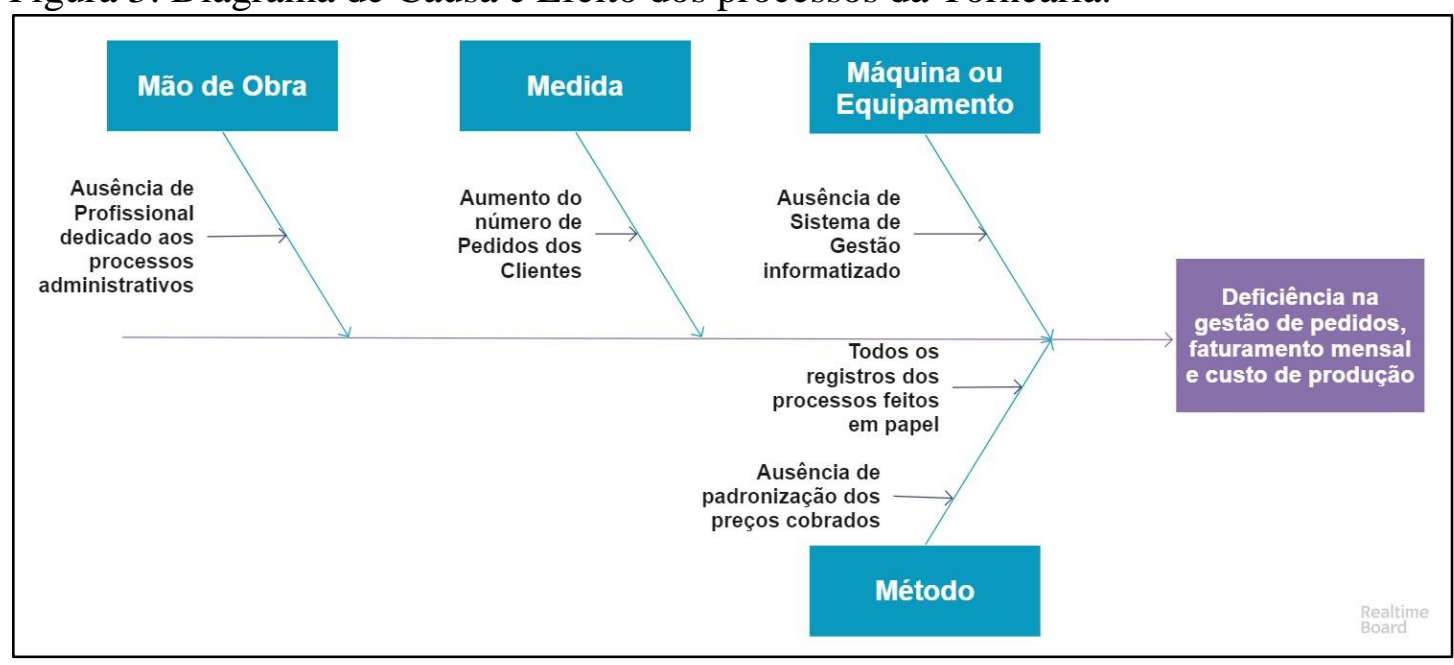

Fonte: Elaborada pelos autores.

Como solução para os problemas encontrados, foi visto como necessidade a automatização de alguns processos administrativos, no intuito de integrar os procedimentos relativos à produção e faturamento da Tornearia. Desde modo, a implantação de um sistema ERP seria fundamental nesse processo de integração, entretanto, o elevado custo para aquisição e implantação dos sistemas ERP consagrados 
não é compatível com o faturamento da empresa em estudo, o que guiou as estratégias na direção de uma opção gratuita do software, das diversas existentes no mercado.

O sistema escolhido como proposta para utilização foi o MarketUP, que consiste em uma plataforma totalmente online, gratuita e sem limitação de uso. Conforme mostra a figura 4, é possível gerenciar todo o processo administrativo, desde o orçamento realizado a um cliente, à emissão de nota fiscal para faturamento, balanço mensal e controle, por meio de relatórios padrão oferecidos pelo software. A plataforma ainda permite o cadastro de um banco de produtos e de clientes. Desta maneira, o processo de atendimento ao cliente e faturamento do pedido deixaria de ser realizado manualmente a passaria ser automatizado e integrado pela ferramenta.

Figura 4: Perfil da Tornearia no software MarketUP

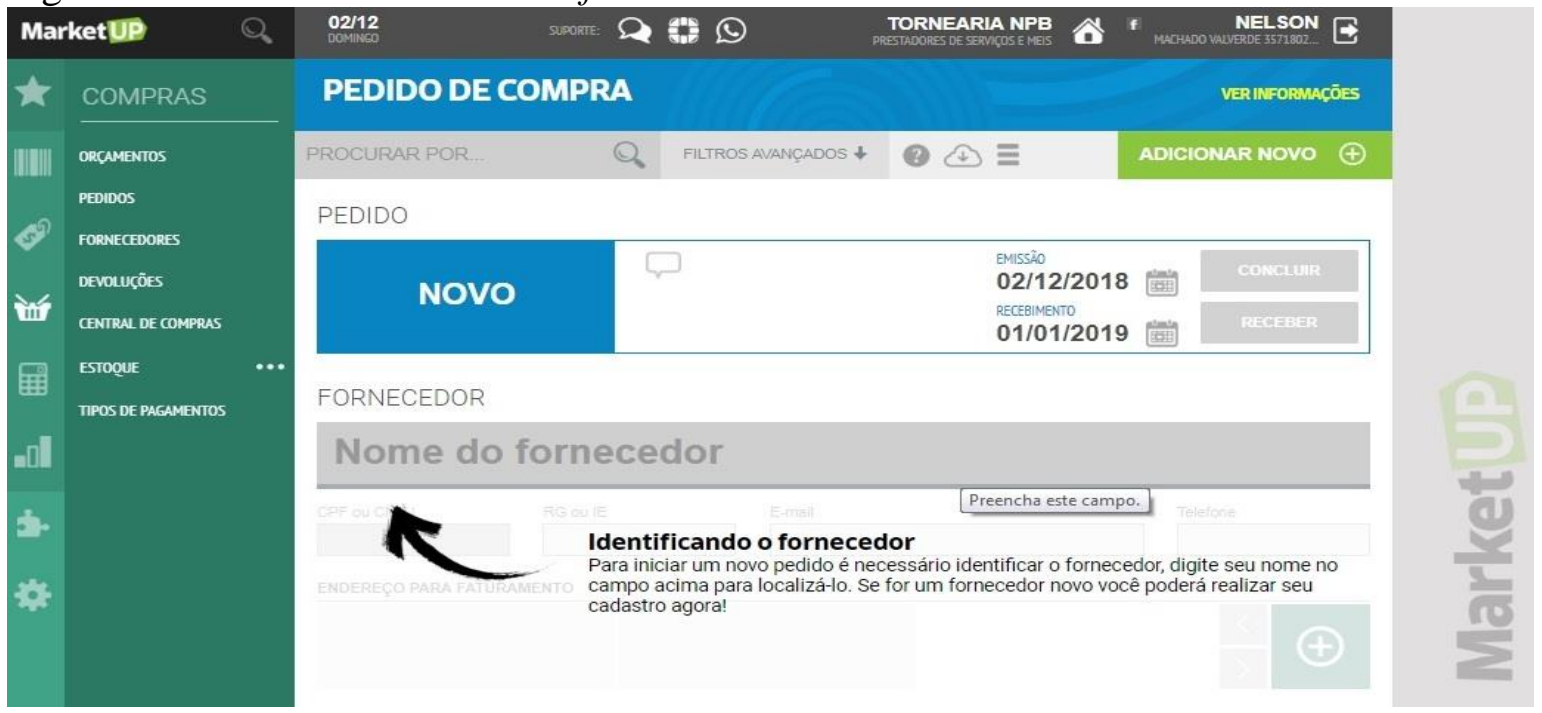

Fonte: MarketUP, on-line.

O software contempla os seguintes módulos: Caixa / vendas, contas a receber, contas a pagar, controle de estoque, controle de custos e o módulo fiscal. A figura 5, apresenta um comparativo através de um fluxograma do atual cenário das atividades de controle de faturamento e de emissão de notas fiscais, ambos realizados manualmente, juntamente em como será realizado após aplicação da ferramenta. 
Figura 5: Fluxograma dos processos antes e depois da integraçãoMarketUP

Controle de Faturamento

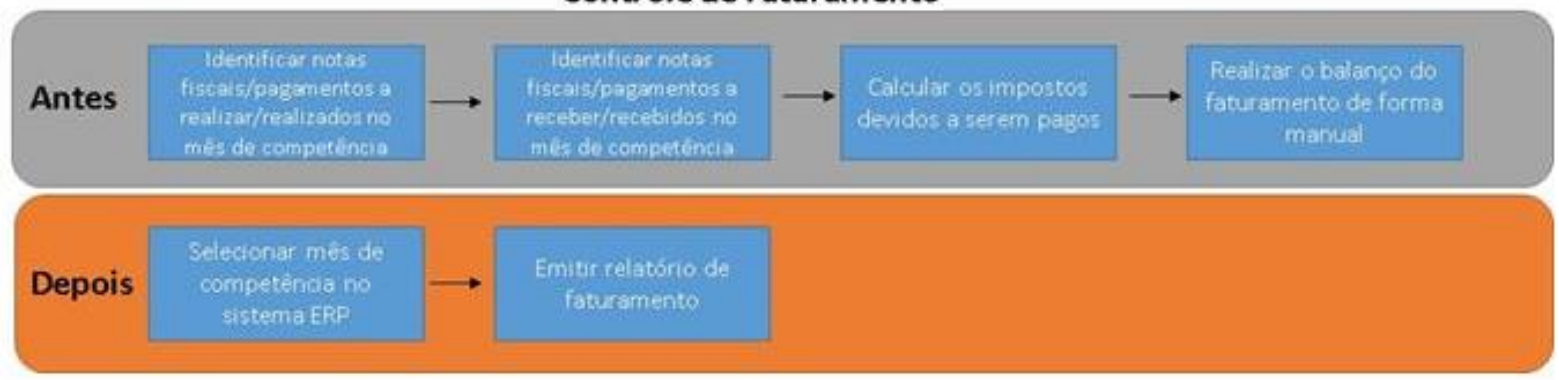

Emissão de notas fiscais

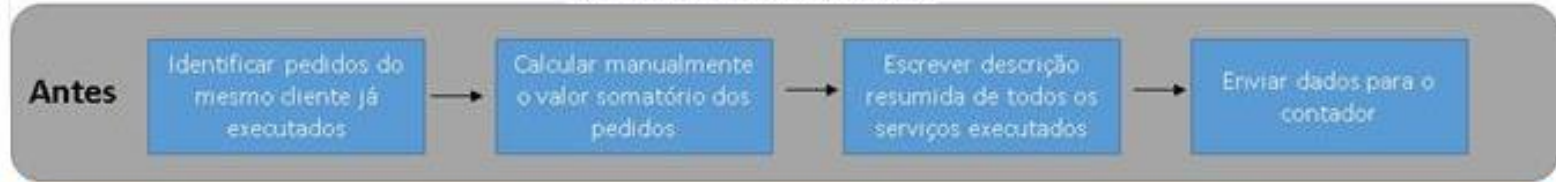

Depois

Selecionar pedido:

que serbo agutunado:

Emiter NF

na NF no sistema ERP

Fonte: Elaborada pelos autores

Com a aplicação da ferramenta, possibilitaria a Tornearia conseguir aliar, de forma eficiente, a gestão financeira e operacional dos seus pedidos, mantendo a transparência com seus clientes através da padronização de custos e prazos de entrega, os quais seriam informados de maneira prévia, logo após o recebimento dos pedidos.

\section{CONCLUSÃO}

Em meio ao atual cenário de mercado brasileiro, as micro e pequenas empresas vêm se tornando, ao longo dos últimos anos, ainda mais relevantes na economia do país. Para se manterem ativas neste mercado competitivo, é necessário investir em práticas que permitem o melhor uso de seus recursos, reduzindo desperdícios, atrasos no cumprimento prazos, bem como o gerenciamento de sua cadeia produtiva.

Objetivou-se, com essa pesquisa, identificar os benefícios e oportunidades de melhoria, com a utilização do sistema ERP (Enterprise Resource Planning) na gestão da produção, verificando aplicabilidades dos conceitos e melhor atendimento ao orçamento disponível do microempreendedor.

A gestão integrada através da implantação de softwares ERP, apresenta-secomo uma ferramenta importante para a gestão da organização, fornecendo informações para um melhor controle das atividades de produção e administrativas.

Contudo, verificou-se que as micro e pequenas empresas possuem dificuldades na adoção de sistemas ERP consagrados no mercado, visto ao seu elevado custo para aquisição e implantação.

Diante deste contexto, foi realizada uma análise em uma Tornearia na qual foram observados alguns pontos deficitários, do ponto de vista de gestão de processos, que influenciam negativamente no processo produtivo e de relacionamento com o cliente. Verificou-se que a implantação sistema ERP gratuito poderia ser dado com alternativa para melhoria de seus processos.

Conclui-se, portanto, que para as micro e pequenas empresas, ter um sistema de ERP, como o MarketUP, de forma gratuita, garante diversos benefícios que facilitam o gerenciamento empresarial, sem custos diretos de implantação e operação. 
Outras pesquisas podem ser realizadas a partir deste estudo, como a implantação deste sistema para análise de viabilidade da ferramenta.

\section{REFERÊNCIAS BIBLIOGRÁFICAS}

ABES - Associação Brasileira de Empresas de Software,(2017).Investimentos em TI no Brasil aumentam 4,5\% em 2017. Disponível em: http://www.abessoftware.com.br/dados-do-setor/estudo2018--dados-2017. Acessado em: 20 de Nov. de 2018

AMORIM, Rodrigues Fernando; ABREU, Camargo Henrique Pedro (2017): “O impacto da implantação de sistemas ERP no cenário de micro e pequenas empresas”, Revista Observatorio de laEconomía Latinoamericana, Brasil, (setembro 2017). Disponível em: <http://www.eumed.net/cursecon/ecolat/br/2017/implantacao-sistemas-erp.html>. Acessado em: 20 de Nov. 2018.

AZEVEDO, G. Micros e pequenas têm impacto significativo na economia. Jornal do Brasil. 2013. Disponível em: <http://www.jb.com.br/economia/noticias/2013/09/07/micros-e-pequenas-tem-impactosignificativo-na-economia/>. Acessado em: 17 de Nov. 2018.

BRASIL. Lei Complementar $\mathbf{n}^{\mathbf{0}} 123$, de 14 de dezembro de 2006. Institui o Estatuto Nacional da Microempresa e da Empresa de Pequeno Porte. Disponível em:

< http://www.planalto.gov.br/ccivil_03/leis/LCP/Lcp123.htm>. Acessado em: 17 de Nov. de 2018.

BRASIL. LEI COMPLEMENTAR $\mathrm{N}^{\circ}$ 147, DE 7 DE AGOSTO DE 2014. Altera a Lei Complementar $\mathrm{n}^{\circ}$ 123, de 14 de dezembro de 2006. Disponível em:

< http://www.planalto.gov.br/ccivil_03/leis/LCP/Lcp147.htm>.

Acessado em: 17 de Nov. de 2018.

CHANDRAKUMAR, T., \&Parthasarathy, S. (2016). An approach to estimate the size of ERP package using package points. Computer Standards $\{\&\}$ Interfaces, 47, 100-107. Disponível em: http://doi.org/http://dx.doi.org/10.1016/j.csi.2015.10.003. Acessado em: 20 de Nov. de 2018.

COMPUTEWORLD. Empresas Totvs, SAP e Oracle detêm $81 \%$ do mercado de ERP no Brasil. Disponível em: https://computerworld.com.br/2018/04/19/totvs-sap-e-oracle-detem-81-do-mercado-deerp-no-brasil/. Acessado em: 20 de Nov. 2018.

EVERTON JUNIOR, AntonioMPE: avanços importantes para as micro e pequenas empresas 20172018 /Antonio Everton Junior. - Rio de Janeiro : Confederação Nacional do Comércio de Bens, Serviços e Turismo, 2017. Disponível em: $<$ http://cnc.org.br/sites/default/files/arquivos/mpe__avancos_importantes_2017-2018.pdf>. Acessado em: 18 de Nov. de 2018.

FERNANDES, R. B.; ANTONIALLI, L. M.; COSTA FILHO, C. G. da; CAIXETA, R. P. A utilização de sistemas de ERP como antecedente da eficiência e eficácia (inter) organizacional: um estudo em dimensões estratégicas em pequenas e medias empresas. RevistaProduçãoOnline, Florianópolis, v. 15, n. 4, p. 1351-1376, out./dez. 2015

FREE SOFTWARE FONDATION. The Free Software Foundation (FSF) is nonprofit with a wordwide mission to promote computer user freedom and to defend the rights of all free software users. Disponível em: <http://www.fsf.org/about/>. Acessado em: 22 de Nov. de 2018

FORNAZARO, André Guinzelini. Sistemas Integrados de Gestão (ERP) Como Ferramenta de Mudança Organizacional em Pequenas Empresas. 2011.São Carlos.Online. Disponível em: Acesso em: 14 de Nov. de 2018

GIL, A. C. Como elaborar projetos de pesquisa.5 $5^{\text {a }}$ ed. São Paulo: Atlas S.A., 2010.

HABERKORN, E. Um bate-papo sobre gestão empresarial com ERP: tudo que você gostaria de saber sobre ERP e a tecnologia da informação, mas ficava encabulado de perguntar. São Paulo: Saraiva, 2007. 
INSTITUTO BRASILEIRO DE GEOGRAFIA E ESTATÍSTICA - IBGE. Estatísticas do Cadastro Central de Empresas. Brasília, 2010.

MORAES, G.D.A.; TERRENCE, A.C.F.; ESCRIVÃO FILHO, E. A Tecnologia da Informação como suporte à gestão estratégica da informação na pequena empresa. Revista de Gestão da Tecnologia e Sistemas da Informação. Vol. 1 No.1. p 28-44, 2004

Matos, T. J. (2010). Metodologia de implantação para software ERP. Universidade Feevale.

NASCIMENTO, M. et al. Fatores determinantes da mortalidade de micro e pequenas empresas da região metropolitana de Florianópolis sob a ótica do contador. Revista Eletrônica de Estratégia \& Negócios, v. 6, n. 2, p. p. 244-283, 2013.

NOGUEIRA, Cícero. PMEs: as protagonistas da economia brasileira.Disponível em: $<$ http://www.senior.com.br/noticias/pmes-as-protagonistas/>. 2013. Acesso em 26/11/2018

PADOVEZE, C. L.; MARTINS, M. A. M. Contabilidade e Gestão para Micro e Pequenas

Empresas. Curitiba: Intersaberes, 2014.

PINHEIRO, Marília G.; DONAIRES, Omar Sacilloto; FIGUEIREDO, Luís Ricardo de. Aplicação da Visão Sistêmica na implantação de Sistemas Integrados de Gestão ERP. Anais do 7o Congresso Brasileiro de Sistemas. São Paulo, p. 409 - 421, 2011.

O‘BRIEN, J. A.; MARAKAS, G. M. Administração de Sistemas de Informação. Porto Alegre: AMGH, 2013.

SANTOS, A. M. dos; MAÇADA, A. C. G. Comportamento mimético no abandono de sistemas ERP: o caso de uma organização brasileira. Em: AMERICAS' CONFERENCE ON INFORMATION SYSTEMS, 16., 2010, Lima, Peru. Anais... Illinois: Association for Information Systems, 2010.

SEBRAE (2013). Anuário do trabalho na micro e pequena empresa: 2010-2011. 4. ed. Departamento Intersindical de Estatística e Estudos Socioeconômicos[responsável pela elaboração da pesquisa, dos textos, tabelas e gráficos]. Brasília, DF; DIEESE. Disponível em: <http:// www.sebrae.com.br/Sebrae/Portal\%20Sebrae/Anexos/Anuario\%20do\%20Trabalho\%20Na\%20

Micro\%20e\%20Pequena\%20Empresa_2013.pdf>. Acessado em: 18 de Nov. de 2018

SEBRAE; DEPARTAMENTO INTERSINDICAL DE ESTATÍSTICA E ESTUDOS SOCIOECONÔMICOS - DIEESE. Anuário do trabalho na micro e pequena empresa: 2010-2011. Brasília, 2011.

SEBRAE. Mais gestão estratégica. Disponível em: $<$ http://www.sebrae.com.br/sites/PortalSebrae/Programas/Elabore-um-plano-dea\%C3\%A7\%C3\%A3oestrat\%C3\%A9gico-para-sua-empresa>. Acesso em: 20 de Nov. 2018.

SEBRAE- Sobrevivência das empresas no Brasil. / Marco Aurélio Bedê (Coord.) - Brasília Sebrae, 2016.

TEIXEIRA, J. E. Políticas de estímulo à inovação em micro e pequenas empresas: contribuições do Programa Agentes Locais de Inovação (Brasil) e da Rede PME Inovação (Portugal). Tese.2017.

TI ESPECIALISTAS. O mercado de sistemas ERP. Disponível em: <http://www.tiespecialistas.com.br/2014/05/o-mercado-de-sistemas-erp-2>. Acessado em: 22 de Nov. de 2018

TURBAN, E. et al. Tecnologia da Informação para Gestão: Transformando os Negócios na Economia Digital. 6 ed. Bookman, 2010. 